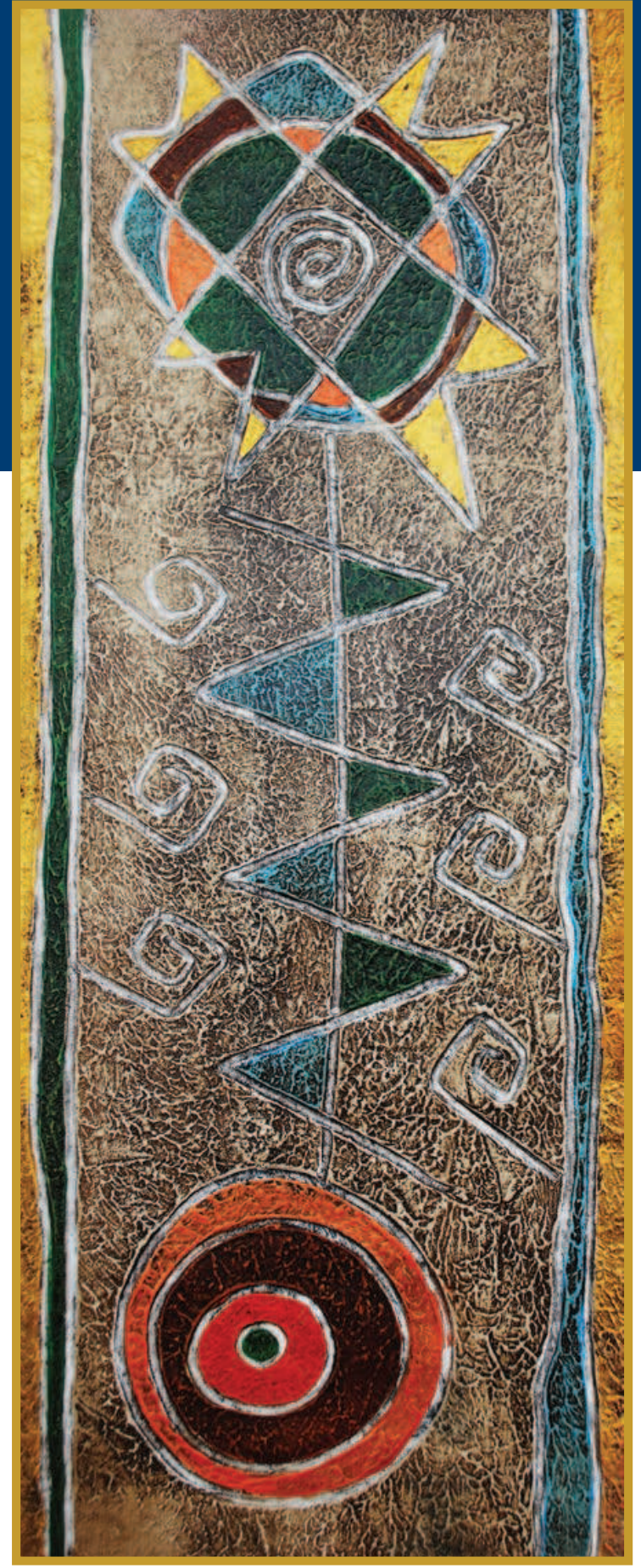

Pastuñan (Camino de los pastos) Mixta 2010

\section{Claves para la catequesis a la luz} de Aparecida

\section{Mstr. Carmita Coronado*}

\section{A modo de introducción}

La reflexión acerca de la historia de la catequesis contemporánea requiere que se aborden contextos culturales y eclesiales diferentes, teniendo en cuenta las investigaciones en pedagogía catequética, recordando las orientaciones del Magisterio: Catecismo de la Iglesia Universal, Directorio General para la catequesis, Cathechesis Tradendae, entre otros; donde se enumeren y analicen algunas publicaciones, releyendo enciclopedias y obras de grandes autores actuales.

El autor Henri Derroitte en su obra Por una nueva catequesis, jalones para un nuevo proyecto catequético, destaca algunas líneas que van marcando a la acción catequética a partir del Concilio Vaticano II:

a. Las rupturas en la transmisión: precisamente cuando todo el mundo se pone de acuerdo para decir que la transmisión de valores y de las instituciones de una generación a otra es la condición para su sobrevivencia, los enfoques clásicos sobre la transmisión religiosa han llegado a sus 


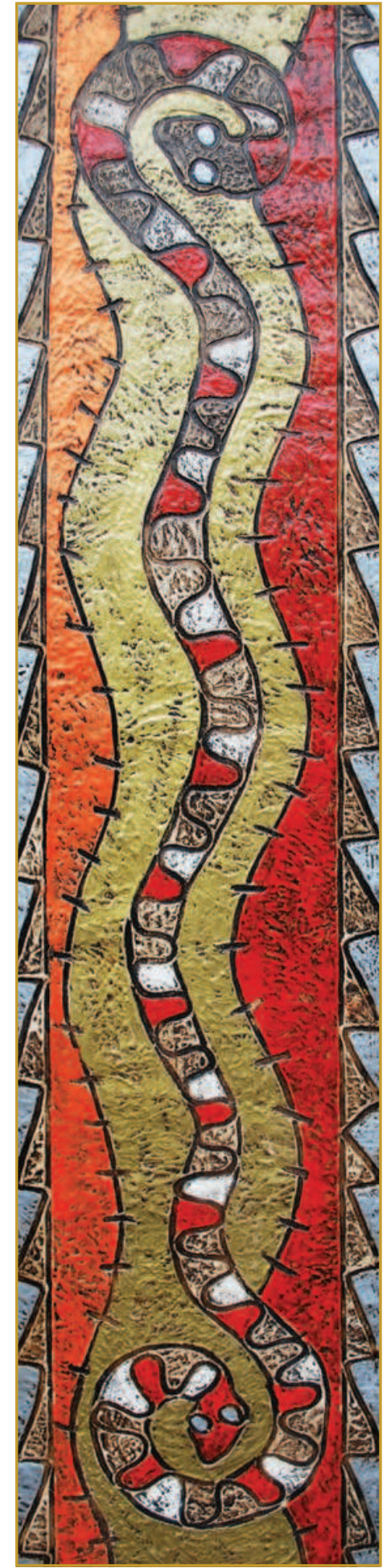

Tinkimari (Serpientes) Mixta 2010 últimos límites. En este sentido, la catequesis se enfrenta hoy se enfrenta hoy a un triple desafío cultural:

> El de la multiplicidad de ofertas religiosas coexistentes en una sociedad tolerante.

$>$ El del primado de la experiencia personal y de la autenticidad del proceso individual en desmedro de una conformidad con valores religiosos garantizados por las instituciones.

$>$ El de la constante complejización de lo real que no considera necesario buscar en el pasado las referencias para inventar el futuro.

Entonces, hay que comprender que las nuevas investigaciones catequéticas no son una concesión a la moda o el resultado de una fascinación ejercida por las ciencias humanas, sino la consecuencia de haber tomado en serio la ruptura epistemológica operada en la concepción de la verdad.

b. La exigencia de la libertad: el binomio libertad-catequesis ¿ha funcionado bien en la práctica de nuestras comunidades? Si es verdad que la fe aparece ante nuestros contemporáneos como una adhesión personal libre, la religión es hoy un espacio de libertad por excelencia. No hay que separar el despertar a la fe del despertar a la libertad. Ya que la fe se dirige a la libertad, la catequesis, en lugar de reducirse a una enseñanza despersonalizada de verdades y de preceptos abstractos, tiene que presentarse como iniciación concreta a la fe viva y a la práctica vivida de la fe.

c. La catequesis y los sacramentos de iniciación: la relación catequesis e iniciación, catequesis y liturgia, catequesis y sacramentos es de tal manera decisiva para la vida cristiana que no se trata de preparar a los niños para actos aislados, para celebraciones ocasionales que sería como paréntesis en su vida. Sino más bien de iniciarlos de manera verdadera en un modo de vivir en comunión con Dios y con los demás.

d. Lugares para quien busca sentido: disponemos de lugares para enseñar a los que quieren aprender, para celebrar con quienes profesan nuestra fe, pero no tenemos lugares para buscar con otros el sentido de lo que vivimos, ellos y nosotros, para iniciarnos en lo que los demás buscan y para iniciarlos en el tipo de búsqueda 
al que nos conduce la fe. Estos lugares no son edificios materiales, son comunidades en las que los cristianos se encuentren con las personas que están de paso y se comuniquen con ellas.

e. ¿Catequesis verbal o testimonio? Dar catequesis es hablar. El hecho de tomar la palabra encierra un peligro real, nadie lo ignora. El Sínodo de Obispos de 1977, dedicado a la Catequesis, la definió bajo tres aspectos: de 'palabra', 'memoria' y 'testimonio'. Desde hace bastante tiempo este último término está siendo objeto de numerosos estudios realizados por los teólogos y los catequistas. Expresiones como compromiso personal, in-culturación, acción eclesial, vida espiritual, oración personal y litúrgica, santidad, manifiestan esta misma realidad: el testimonio. Hablar del catequista testigo es introducir dos dimensiones esenciales en toda vida cristiana: la de la humildad y la de la espiritualidad, el testigo es la mujer o el hombre que confía en el amor y, con fidelidad, quiere vivir de la salvación que recibe. La misión nace de una alianza de confianza. Lo que es cierto para el catequista individual como testigo de un camino personal vale también para la comunidad parroquial.

f. La catequesis y su leguaje: ¿qué decir? ¿cómo hablar? La cuestión del lenguaje es importante. El vocabulario del cristianismo depende de un contexto cultural completamente extraño al nuestro. La Biblia utiliza imágenes de un universo pastoral completamente distinto. La teología, los textos litúrgicos, los textos del Papa y de los obispos son, para la mayoría de la gente, en parte, incompresibles. Hace mucho tiempo que la catequesis ha notado esta dificultad. Y, sin embargo, "hay que decir Dios, un Dios a quien no pueden apuntar las palabras humanas no es el Dios de la Biblia". Los intentos de superación de estas dificultades proponen emplear diversos lenguajes: palabras, gestos, íconos, medios de comunicación, etcétera. El P. Emilio Alberich sugiere que se privilegie el lenguaje simbólico, sugerente, propio de la comunicación religiosa.

g. La diferencia y la complementariedad entre catequesis y clase de religión: la escuela, también la cristiana, abierta a todos, es un servicio público; la clase de religión (distinta de la animación pastoral) no tiene como objetivo inmediato comunicar la fe, sino sobre todo favorecer un mejor ejercicio de la libertad religiosa. El curso de religión no presupone la fe de los alumnos y no la impone. Se dirige a todos. Es un lugar de reflexión sobre la fe, un lugar de estudio de la fe cristiana en relación con los otros saberes culturales, un lugar de debate para permitir a todos un mejor ejercicio de la libertad religiosa.

La catequesis se inscribe en el clima eclesial; el proceso de iniciación es un proceso de apropiación progresiva, libre, existencial y que sigue un ritmo litúrgico, de la fe cristiana y de los diversos aspectos de la vida cristiana gracias al contacto y al apoyo de una comunidad que cree, vive y celebra.

\section{Lo que dice el Documento de Aparecida (2007)}

El capítulo 6 está dedicado al Itinerario formativo de los discípulos misioneros que tiene como objetivo "El Encuentro con Jesucristo".

Textualmente dice:

El acontecimiento de Cristo es, por lo tanto, el inicio de ese sujeto nuevo que surge en la historia y al que llamamos discípulo. No se comienza a ser cristiano por una decisión ética o una gran idea, sino por el encuentro 


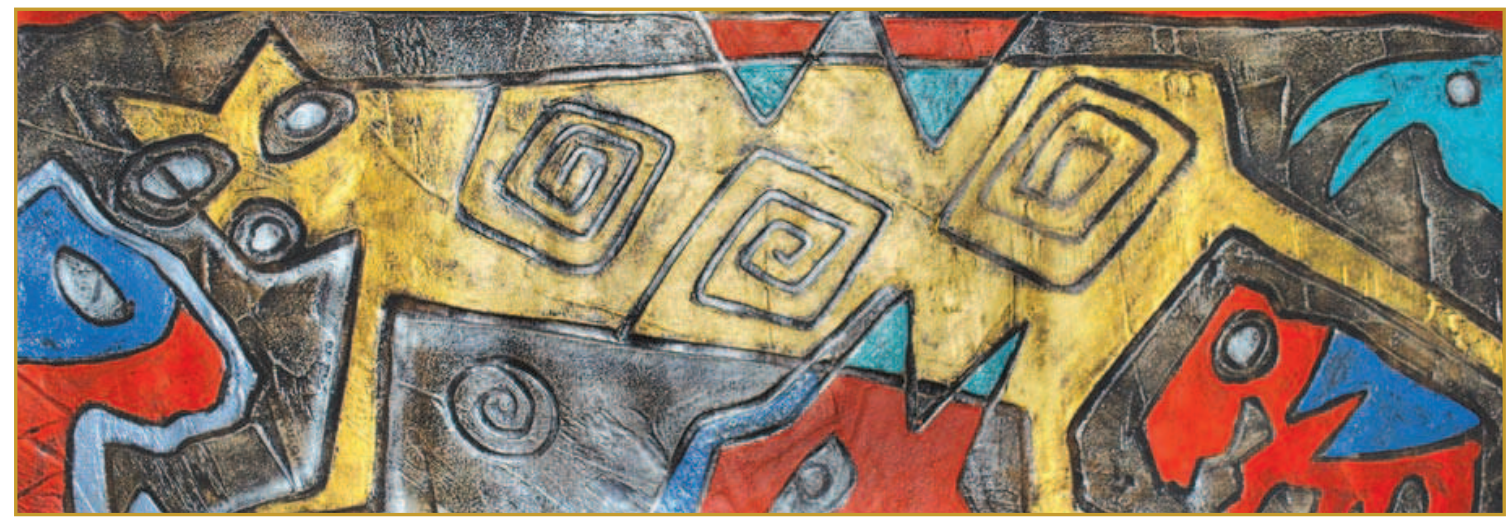

Wiwakuna (Animales) Mixta 2010

con un acontecimiento, con una Persona, que da un nuevo horizonte a la vida y, con ello, una orientación decisiva (DA n. 243).

Al referirse al proceso de formación de los discípulos misioneros aclara que:

La vocación y el compromiso de ser hoy discípulos y misioneros de Jesucristo en América Latina y El Caribe, requieren una clara y decidida opción por la formación de los miembros de nuestras comunidades, en bien de todos los bautizados, cualquiera sea la función que desarrollen en la Iglesia. Miramos a Jesús, el Maestro que formó personalmente a sus apóstoles y discípulos. Cristo nos da el método 'vengan y vean'. Con Él podemos desarrollar las potencialidades que están en las personas y formar discípulos misioneros. Con perseverante paciencia y sabiduría, Jesús invitó a todos a su seguimiento a quienes aceptaron seguirlo, los introdujo en el misterio del Reino de Dios, y, después de su muerte y resurrección, los envió a predicar la Buena Nueva con la fuerza de su Espíritu. Su estilo se vuelve emblemático para los formadores y cobra especial relevancia cuando pensamos en la paciente tarea formativa que la Iglesia debe emprender, en el nuevo contexto socio-cultural de América Latina. (ibíd., n. 276).
Salta un primer desafío: revisión de las metodologías que de pronto han estado alejadas de la Pedagogía Divina.

El itinerario formativo del seguidor de Jesús hunde sus raíces en la naturaleza dinámica de la persona y en la invitación personal de Jesucristo, que llama a los suyos por su nombre, y éstos lo siguen porque conocen su voz. El Señor despertaba las aspiraciones profundas de sus discípulos y los atraía a sí, llenos de asombro. El seguimiento es fruto de una fascinación que responde al deseo de realización humana, al deseo de vida plena. El discípulo es alguien apasionado por Cristo, a quien reconoce como el maestro que lo conduce y acompaña (ibíd., n. 277).

En los siguientes numerales se habla de una formación integral, kerygmática (primer anuncio) y permanente, atenta a dimensiones diversas tales como: la humana y comunitaria, la espiritual, intelectual, pastoral y misionera; una formación respetuosa de los procesos y que contempla el acompañamiento de los discípulos.

\section{La iniciación cristiana y la catequesis}

A partir del numeral 6.3, se aclara el sentido de la iniciación cristiana como un desafío: 
Cuestiona a fondo la manera cómo estamos educando en la fe y cómo estamos alimentando la vivencia cristiana. Se impone la tarea irrenunciable de ofrecer una modalidad operativa de iniciación cristiana que, además de marcar el qué, dé también elementos para el quién, el cómo y el dónde se realiza. Así asumiremos el desafío de una nueva evangelización, a la que hemos sido reiteradamente convocados (ibíd., n. 287).

La iniciación cristiana, propiamente hablando, se refiere a la primera iniciación de los misterios de la fe (ibíd., n. 288).

Asumir esta iniciación cristiana exige no sólo una renovación de modalidad catequística de la parroquia. Proponemos que el proceso catequístico formativo adoptado por la Iglesia para la iniciación cristiana sea asumido en todo el continente como la manera ordinaria e indispensable de introducir en la vida cristiana, y como la catequesis básica y fundamental. Después vendrá la catequesis permanente que continua el proceso de maduración en la fe, en la que se debe incorporar un discernimiento vocacional y la iluminación para proyectos personales de vida (ibíd., n. 294).

El sustento de la catequesis permanente, tomando como elementos la situación de la catequesis en general y de los catequistas en particular, está en el número 298:
La catequesis no debe ser sólo ocasional, reducida a los momentos previos a los sacramentos o a la iniciación cristiana, sino más bien 'un itinerario catequético permanente'. Por esto, compete a cada iglesia particular, con la ayuda de las Conferencias Episcopales, establecer un proceso catequético orgánico y progresivo que se extienda por todo el arco de la vida, desde la infancia hasta la ancianidad, teniendo en cuenta que el Directorio General de Catequesis considera la catequesis de adultos como la forma fundamental de la educación en la fe. Para que, en verdad, el pueblo conozca a fondo a Cristo y lo siga fielmente, debe ser conducido especialmente en la lectura y meditación de la Palabra de Dios, que es el primer fundamento de una catequesis permanente.

En lo que tiene que ver con nuestra Iglesia, en Ecuador se tiene ya un Itinerario de Catequesis parroquial, que fue aprobado por los señores Obispos en su Asamblea Plenaria del mes de noviembre de 1997, en el cual se proponen seis niveles de formación, los mismos que responden a las características sico-religiosas de los catequizandos. Este itinerario se ha implementado en un alto porcentaje de jurisdicciones eclesiásticas el mismo que está acompañado de la preparación de los catequistas.

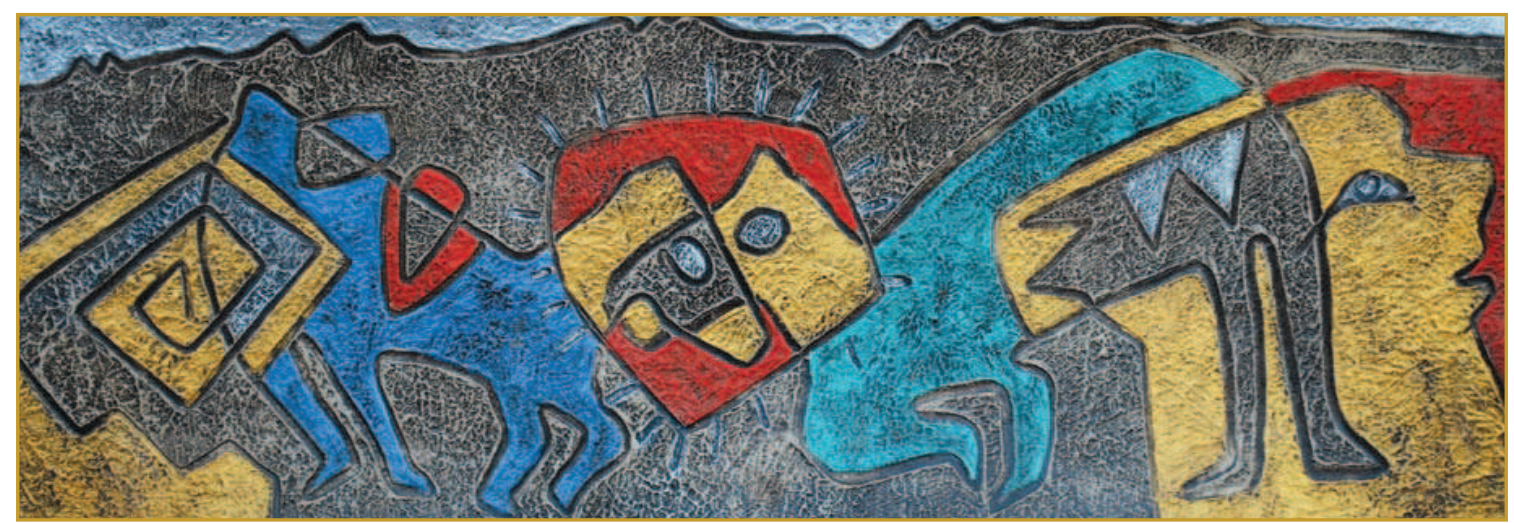

Wiwa kuyay (Sentimiento fraternal)

Mixta 2010 


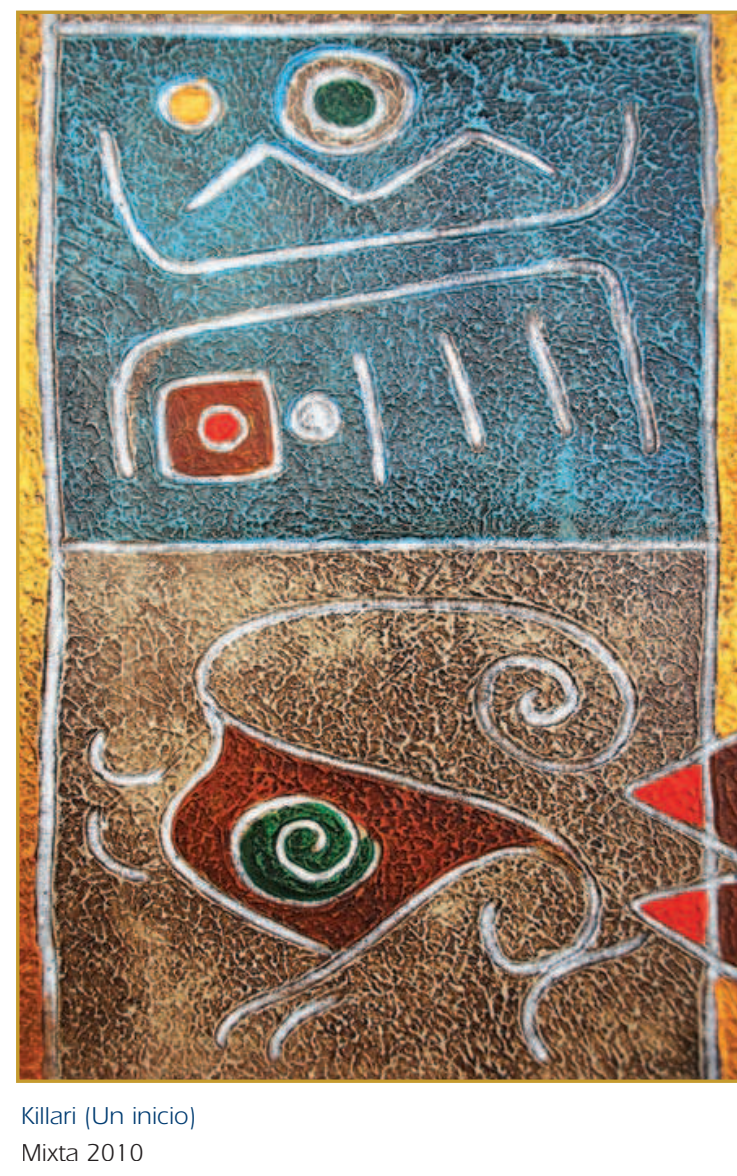

La catequesis no puede limitarse a una formación simplemente doctrinal sino que ha de ser una verdadera escuela de formación integral. Por tanto, se ha de cultivar la amistad con Cristo en la oración, el aprecio por la celebración litúrgica, la vivencia comunitaria, el compromiso apostólico mediante un permanente servicio a los demás. Para ello, resultarían útiles algunos subsidios catequéticos elaborados a partir del Catecismo de la Iglesia Católica y del Compendio de la Doctrina Social de la Iglesia, estableciendo curso y escuelas de formación permanente para catequistas (ibíd., n. 299).

Desde el Departamento de Catequesis de la Conferencia Episcopal Ecuatoriana, se han elaborado subsidios tanto para los catequizandos como para los catequistas, en este sentido se ha publicado la nueva edición revisada tanto en contenidos como en metodología de los catecismos para cada uno de los seis niveles de la catequesis parroquial, con sus respectivas
Lecturas clave de Aparecida

guías y material para padres de familia. Para los catequistas, una colección con temas específicos de su formación que abarca las dimensiones del 'Ser', el 'Saber', el 'Saber Hacer' y el 'Convivir', cada una de ellas con un pensum para preparar al catequista en su tarea de comunicar el Evangelio. A esto se suma el acompañamiento permanente a través de cursos y talleres que responden a requerimientos específicos de formación de catequistas en las diócesis que así lo ameritan.

Igualmente, la planificación de la Pastoral Catequética para su respectiva ejecución, ha organizado zonas pastorales para hacer un trabajo conjunto así como también, se realizan acciones coordinadas con otros ámbitos pastorales porque la catequesis es un eje transversal en la acción evangelizadora de la Iglesia.

\section{Conclusión}

La reflexión final es que quedan todavía muchos cabos que atar, una infinidad de proyectos de mejoramiento, y mucha reflexión en líneas catequéticas para América Latina, ya que este espacio es el mayor que tiene la Iglesia en todas partes a donde el cristianismo ha llegado.

Usted amigo lector, bautizado o no, también tiene parte en esta tarea.

\section{Bibliografía}

- ALBERICH, Emilio (2003), Catequesis evangelizadora, manual de catequesis fundamental, Quito: Abya-Ayala.

- Catequesis para América Latina. CELAM. 2002.

- Cathechesi Tradendae (Catequesis de nuestro tiempo). Juan Pablo II.

- DERroitTe, Henri (2004), Por una nueva catequesis, Madrid: Sal Terrae.

- Directorio General de Catequesis. 1997

- CEE, Directorio Nacional de Catequesis. Edición corregida. 2009. 